\title{
Training needs assessment of rural women regarding health and hygiene practices in Bikaner district of Rajasthan
}

\section{Suchitra and Neena Sareen}

Received: 03.10.2020; Revised: 05.11.2020; Accepted: 25.11.2020

See end of the paper for authors' affiliations

\section{Suchitra}

Department of Extension

Education, Vivekananda Global

University, Jaipur (Rajasthan)

India

Email : suchi3mothsara@gmail.

com
ABSTRACT : The present study was conducted in six panchayat samities out of which Bikaner panchayat samiti was selected. Out of thirty one Gram panchayat in Bikaner panchayat samiti four Gram panchayat were selected one village was selected on the basis of random sampling technique. Findings revealed that the result of training needs of rural women regarding the major findings of the present study revealed that in general information majority of the respondents belonged to middle age group, educated up to primary, belonged to 4001-6000/monthly income group, nuclear family system, other backward caste, involved in agriculture occupation, had above 2.1-5 hectare of land holding, no membership of social organization, no participated in training programme and medium level of mass media contact, urban contact and extension contact. It was reported that the 'Family planning', 'Care of pregnant and lactating mother', 'Child care' were perceived by the rural women as the most important training areas for improved health status whereas, 'Environmental sanitation', was perceived as the somewhat important training area by the rural women.

KEY WORDS: Health, Training, Assessment, Need, Sanitation, Hygiene

- HOW TO CITE THIS PAPER : Suchitra and Sareen, Neena (2020). Training needs assessment of rural women regarding health and hygiene practices in Bikaner district of Rajasthan. Asian J. Home Sci., 15 (2) : 336-341, DOI: 10.15740/HAS/AJHS/15.2/336-341. Copyright@ 2020: Hind Agri-Horticultural Society. 